\section{PATTERNS OF LANGUAGE CHOICE IN A THAI-SIKH COMMUNITY IN BANGKOK}

\section{Rachanee Dersingh $^{1}$}

\begin{abstract}
This study determines the pattern of language choice in six domains among the Thai-Sikh people of Bangkok. The relationship between the patterns of language choice and various social variables are also examined. Data from a questionnaire survey of 40 participants from the Thai-Sikh community residing in a Thai-Sikh residential neighborhood was collected along with semi-structured interviews of 1-2 representatives of each age group. The data was analyzed using descriptive and inferential statistics. The results indicate that Thai is most commonly used in four out of the six domains; namely, family, friend, work, and market. English is most commonly used in the school domain and Punjabi in the temple domain. A significant relationship is observed between the patterns of language choice and 3 other variables including gender, age, and educational level.
\end{abstract}

\section{Introduction}

Thailand is a country with several minorities including Thai-Sikhs. The Thai-Sikhs are Sikh immigrants to Thailand from India. The migration of Indians to Thailand started in the late $19^{\text {th }}$ century (Yahya and Kaur 2011). With

\footnotetext{
${ }^{1}$ Ph.D. Candidate, Department of Linguistics, Faculty of Arts, Chulalongkorn University, Bangkok, Thailand
}

time, the number of Indians migrating to Thailand increased, particularly during the partition of India in 1947 when the state of Punjab was divided between Pakistan and India. The Muslims living in India had to move to Pakistan and Hindus or Sikhs living in the Pakistan region had to make an exodus to the New India territory (Grewal 1991). Instead of moving to the New India, many families moved to other countries, for example, Canada, the United States of America, England, Singapore, Malaysia, and Thailand. Once in a new host country, the new settlers and the generations that followed adapt to their new surroundings. They assimilate to the new culture as they also learn the language of their new country. Hence, the Thai-Sikhs are known to be a bilingual or multilingual community. This is because most ThaiSikh community members use Thai as the official language, English as the international language, and Punjabi as the ethnic language of the community. Stewart (1968) defines official language as "a legally appropriate language for all politically and culturally representative purposes on a nationwide basis"; and international language, "as a linguistic system used as a major medium of the communication which is in international scope such as foreign trade and tourism".

Most current members of the ThaiSikh community are more exposed to Thai and English than to Punjabi. Over the several generations since the first migrant population moved to Thailand, Punjabi is used much lesser today than before with its use decreasing with time. This raises questions regarding what languages people of the Thai-Sikh community prefer to use in a variety of contexts. Nevertheless, there have been no studies of language choice in various domains 
within the Thai-Sikh community in Thailand.

This study examines the patterns of language choice in the Thai-Sikh community in six domains: family, friendship, work, temple, school and market. It is based on a language use questionnaire from 40 Thai-Sikh respondents residing in a Charansanitwong Soi 1 neighborhood, Wat Tha Pra subdistrict, Bangkok Yai district, Bangkok. I posit that Punjabi is used the most in family and temple domains. Also, the speaker social characteristics which are gender, age and educational level do have significant relationship with choice of language in all domains

\section{Language choice}

The members of a multilingual community are generally able to use more than one language. According to Holmes (2001), the domains indicate one's language choice as a certain domain signifies interlocutors, the social context and discussion topics. Fishman (1972) defines domain as "institutional contexts", or interaction between participants and particular setting. That is, language choice is made according to whom one is communicating with, where the conversation is taking place, and what topic is being discussed. There have been numerous studies of language choice and domain. One well-cited study of a Puerto Rican community in New York by Greenfield (1972) reported that Spanish is preferred in family and friendship domain, while English is favored in work and education domains. Similar findings were found by Parasher (1980) in two cities in India. The results show that family domain is the only domain that mother tongue and any other language apart from English is used. In contrast, English is used in several domains such as friendship, neighborhood, employment and education. David et al (2003) studied the language choices of Punjabi Sikh community of Petaling Jaya, Malaysia in family domain. The result shows that today's middle-aged group of the Sikh community in Petaling Jaya uses Punjabi when they converse with their parents; however, English is more prevalent when they speak to their children at home. Rasinger (2010) found that L1 is the most language use at home among Eastern European migrants in Great Britain both to their spouse or children. In other domains such as studying, earning money, making friends, education and travelling, English is the most language use. $\mathrm{L} 1$ is preferred over English in the context of being accepted by people from the same ethnicity. Dumanig et al (2013) examined language choice among Filipino-Malay mixed marriages in family domain in Malaysia. The common similarity among thirty families, which are observed and interviewed, is that the wives are Filipino while the husbands are Malay, Malay-Chinese or Malay-Indian. The findings show that English is a dominant language in every family. The second preference is either Malay or their ethnic language or the code mixing/switching among Malay, English and their ethnic language. Apart from family domain, there are studies of language choice's pattern in office or work domains. Rahman (2008) who studied patterns of language choice in office domain among Malay and non-Malay undergraduates at University Putra Malaysia (UPM) in Malaysia found that Malays prefer to 
employ Bahasa Melayu in writing official letters and/or conversing with officials regardless their mother tongue. In contrast, non-Malays prefer English in similar settings. Kingsley (2013) conducts a study on patterns of language choice in different genres in three international banks in Luxembourg. Data collected is related to the language use in reports, emails, presentations, meetings, phone calls and informal talk. The findings show that English is the language used most in all kinds of communication; especially it is used as a stand-alone language for reports. Code mixing of English and others such Swedish, French, German, Luxembourgish and others are frequently used in other genres. Another finding is the factors that influenced the choice of language of employees are the mother tongue and nationality of the participants and the goal of the conversation. These findings indicate that speaker's social characteristics are found to have an influence on language choice. Yeh et al. (2004) reports that there is a significant relationship between language proficiency and age, gender and educational level that leads people with native languages such as Minnanyu, Hakka and Polynesian languages in Taiwan to move towards using the national language of Mandarin in all domains. David et al. (2003) indicates that age has an influence on the use of ethnic language at home. They report that the Sikhs of younger age groups in Malaysia use English more than Punjabi in family domain, while the inverse is true in the older age groups.

\section{Methodology}

Data were collected through a questionnaire survey and semi- structured interview from participants of the Thai-Sikh community residing in Charansanitwong Soi 1 . There were 40 participants to complete the questionnaire and 8 out of 40 participants to be involved in semistructured interview. The study population was selected by employing systematic sampling; that is, every first and forth house of each block in the townhome residential community was chosen. The interviewees were the representatives of each age group. The questionnaire consists of two parts: demographic information and 52 statements concerning language choice in various domains, given a variety of interlocutors and situations. Participants were able to select more than one language in case they often use two or more languages in that particular domain, situation, or with the specified persons in the given scenario. For qualitative data, the interview questions were related to the choice of language use in each domain. Data from questionnaires and interview were coded and tabulated for computation and analysis. The analysis was carried out using descriptive and inferential statistics.

\section{Demographic data}

The demographic information section provides details on gender, age, and education level. Of 40 participants, there were 18 males and 22 females with age divided into four range groups: 16-30, 31-45, 46-60, and over 60. About two third of the participants were in age groups of 16-30 and 46-60. That is, 14 participants $(35 \%)$ and 13 participants $(32.5 \%)$, respectively. The number of participants in age groups of $31-45$ and 46-60 were $6(15 \%)$ and 7 $(17.5 \%)$, respectively. The educational 
level could be classified into three levels: grade 1-12, college/ university undergraduate, and postgraduate to include master's and Ph.D. degrees. Almost half of the participants, 18 participants $(45 \%)$, had a high school or lower education, followed by 15 participants $(37.5 \%)$ with college or bachelor degrees, and 7 participants $(17.5 \%)$ with a post graduate degree

\section{Overview of language choice}

There are several languages spoken within the community with the core languages being Thai, English, Punjabi, and the code mixing between or among those languages. The language most often used among the Thai-Sikh community appears to be Thai at $29.9 \%$, followed by English at $24.5 \%$, and then Punjabi at $17.1 \%$. A mix of Thai-English is used $15.9 \%$ while other mixes at $12 \%$ (see Table 1).

Table 1: Language use in general

\begin{tabular}{lcc}
\multicolumn{1}{c}{ Languages } & Frequency & Percentage \\
\hline Thai & 743 & $29.9 \%$ \\
\hline English & 609 & $24.5 \%$ \\
Punjabi & 424 & $17.1 \%$ \\
Thai-English & 396 & $15.9 \%$ \\
Thai - Punjabi & 167 & $6.7 \%$ \\
English - Punjabi & 43 & $1.7 \%$ \\
Thai - English - Punjabi & 103 & $4.1 \%$ \\
\hline
\end{tabular}

Considering language choice against other variables such as domain, gender, age and education level provides varied results. The pattern of language choice within a domain, in general, shows that Thai is most often used within the family, among friends, at work and in the market domains. On the other hand, English appears most often used in the school domain. As expected, Punjabi is most often used in the temple domain at the Sikh temple (see Table 2). Given the Chi-square $\left(\chi^{2}\right)$ value of 494.294 $(\mathrm{df}=30)$, one can interpret with a pvalue less than 0.01 that there is a strong association between language choice and domain.

Looking at the language choice vs. gender, it appears that females, in general, use a single language more when compared to their male counterparts who seem to mix languages more often (see Table 3). There is a statistically significant relationship between language choice and gender as the $\chi^{2}$ value is 124.279 for df 30 , obtaining a p-value less than 0.01 .

As for age groups, the proportion of the use of Thai is similar in all age groups. The significant difference is that Punjabi is more often used among the older participants, while Thai and English are used more often among the younger (see Table 4). If we examine mixed languages, the older age groups tend to mix more of Punjabi with Thai, while the younger age groups tend to mix English with Thai more often. This appears to indicate that the older age groups are more fluent in Punjabi than in English or, equivalently, the younger group is more fluent in English than Punjabi. The reason could be that being the first or second generation of immigrants to Thailand, acquiring the national language was more important than an international language. The $\chi^{2}$ value indicates the significant relationship between language choice and age group. 
Table 2: Language choice and domain

\begin{tabular}{lcccccc} 
& Family & Friends & Work & Temple & School & Market \\
\hline Thai & $\mathbf{2 6 . 9} \%$ & $35.7 \%$ & $\mathbf{4 6 . 1} \%$ & $12.8 \%$ & $\mathbf{1 7 . 2} \%$ & $33.1 \%$ \\
\hline English & $\mathbf{1 6 . 2} \%$ & $30.7 \%$ & $\mathbf{2 6 . 7} \%$ & $22.1 \%$ & $\mathbf{4 7 . 4} \%$ & $15.6 \%$ \\
\hline Punjabi & $\mathbf{2 3 . 9} \%$ & $\mathbf{7 . 9} \%$ & $\mathbf{3 . 7} \%$ & $39.3 \%$ & $\mathbf{1 3 . 8} \%$ & $15.8 \%$ \\
\hline $\begin{array}{l}\text { Thai- } \\
\text { English }\end{array}$ & $\mathbf{1 7 . 1} \%$ & $17.5 \%$ & $\mathbf{1 4 . 0} \%$ & $\mathbf{8 . 7} \%$ & $\mathbf{2 1 . 6} \%$ & $17.1 \%$ \\
$\begin{array}{l}\text { Thai- } \\
\text { Punjabi }\end{array}$ & $\mathbf{9 . 9} \%$ & $\mathbf{7 . 1} \%$ & $\mathbf{4 . 1} \%$ & $3.7 \%$ & $\mathbf{0 . 0} \%$ & $8.6 \%$ \\
$\begin{array}{l}\text { English- } \\
\text { Punjabi }\end{array}$ & $\mathbf{1 . 5} \%$ & $\mathbf{0 . 0} \%$ & $\mathbf{0 . 0} \%$ & $7.4 \%$ & $\mathbf{0 . 0} \%$ & $2.4 \%$ \\
T-E-P & $\mathbf{4 . 4} \%$ & $1.3 \%$ & $\mathbf{5 . 3} \%$ & $6.0 \%$ & $\mathbf{0 . 0} \%$ & $\mathbf{7 . 4} \%$ \\
\hline
\end{tabular}

$$
\left(\chi^{2}=494.294, \mathrm{df}=30, \mathrm{p}<0.01\right)
$$

Table 3: Language choice and gender

\begin{tabular}{lcccc}
\multicolumn{2}{c}{ Male } & \multicolumn{2}{c}{ Female } \\
\hline Languages & Frequency & $\%$ & Frequency & $\%$ \\
Thai & 330 & 31.6 & 413 & 28.7 \\
English & 194 & 18.6 & 415 & 28.8 \\
Punjabi & 123 & 11.8 & 301 & 20.9 \\
Thai-English & 240 & 23.0 & 156 & 10.8 \\
Thai-Punjabi & 80 & 7.7 & 87 & 6.0 \\
English- & 19 & 1.8 & 24 & 1.7 \\
Punjabi & 58 & 5.6 & 45 & 3.1 \\
T-E-P & & & $\left(\chi^{2}=124.279, \mathrm{~d} \mathrm{f}=30, \mathrm{p}<0.01\right)$ \\
\hline
\end{tabular}

Table 4: Language choice and age group

\begin{tabular}{lcccc} 
Languages & $16-30$ & $31-45$ & $46-60$ & $>60$ \\
\hline Thai & $29.3 \%$ & $28 \%$ & $30.9 \%$ & $31.4 \%$ \\
English & $30.3 \%$ & $34.1 \%$ & $20.8 \%$ & $8.5 \%$ \\
Punjabi & $4.7 \%$ & $9.2 \%$ & $22 \%$ & $43.5 \%$ \\
$\begin{array}{l}\text { Thai- } \\
\text { English }\end{array}$ & $26.4 \%$ & $18.7 \%$ & $9.3 \%$ & $2.3 \%$ \\
$\begin{array}{l}\text { Thai- } \\
\text { Punjabi }\end{array}$ & $3.1 \%$ & $2.8 \%$ & $10.4 \%$ & $11.8 \%$ \\
$\begin{array}{l}\text { English- } \\
\text { Punjabi }\end{array}$ & $2.7 \%$ & $3.3 \%$ & $0.5 \%$ & $0.3 \%$ \\
T-E-P & $3.5 \%$ & $3.8 \%$ & $6.1 \%$ & $2.3 \%$ \\
& & & $\left(\chi^{2}=566.81, \mathrm{df}=18, \mathrm{p}<0.01\right)$
\end{tabular}


Education level also appears to play an important role in language selection. The higher the education level, the higher appears to be the tendency to use of Thai, the national or official language. At the same time, the use of Punjabi, the ethnic language, declines (see Table 5). There is a significant relationship between language choice and education level as suggested by the $\chi^{2}$ value of 267.58 at df12 with p-value less than 0.01 .

Table 5: Language choice and Educational Level

\begin{tabular}{lccc}
\hline Languages & Grade 1-12 & $\begin{array}{l}\text { College } \\
\text { \&Bachelor }\end{array}$ & Master \& PhD. \\
\hline Thai & $23.7 \%$ & $29.6 \%$ & $42.2 \%$ \\
\hline English & $21.2 \%$ & $23.1 \%$ & $30.5 \%$ \\
\hline Punjabi & $27.4 \%$ & $14.2 \%$ & $10.4 \%$ \\
\hline Thai-English & $10.1 \%$ & $22.5 \%$ & $9.5 \%$ \\
Thai-Punjabi & $9.5 \%$ & $5.7 \%$ & $4.4 \%$ \\
\hline English- & $1.4 \%$ & $2.6 \%$ & $1.1 \%$ \\
Punjabi & $6.6 \%$ & $2.2 \%$ & $1.9 \%$ \\
\hline T-E-P & & & \\
\hline
\end{tabular}

$$
\left(\chi^{2}=267.58, \mathrm{df}=12, \mathrm{p}<0.01\right)
$$

\section{Patterns of language choice in various domains}

To better understand the patterns of language choice among all the domains, a general explanation of language use in each domain is provided along with an investigation of patterns of language choice in each domain with other independent variables such as gender, age, and education level.

\section{Patterns of language choice in the family domain}

The respondents were asked to identify what language(s) they use with their family members: father, mother, brother, sister, grandfather, grandmother, son or daughter and spouse. The survey statement also included two situations that usually occur at home; namely, when discussing general topics at the dining table and when discussing personal problems with family members. The language that the respondents used the most with their family members is Thai, followed by Punjabi, then ThaiEnglish, and then English at 26.9\%, $23.9 \%, 17.1 \%$, and $16.2 \%$, respectively (referred to Table 2). The difference in the figures between Thai and Punjabi is not significant. The difference in frequencies between Thai-English and English is also not significant. However, there is a noticeable pattern of language use in family domain. The factors that indicate the use of language are the interlocutors and situations. The respondents converse in Thai with their parents, siblings, spouse or son and daughter more; while Punjabi is used the most with grandparents and mother. Interchangeably with Thai and Punjabi, English and code mixing of Thai and English is used a lot with spouse, son and daughter. According to the situations, Thai is used the most when discussing informal topics and personal problems with family members, followed by the mix of Thai and English. Hence, what is significant in family domain is that Thai and Punjabi are more common than English. Also, Thai-English and Thai-Punjabi are often used within family domain. 


\section{Family domain and gender}

Table 6 presents the frequency of language use between males and females in the family domain. The proportion for the most language use between males and females are similar; that is $29.6 \%$ and $29.45 \%$.

Table 6: Language choice by gender in family domain

\begin{tabular}{lcc}
\multicolumn{1}{c}{ Languages } & Male & Female \\
\hline Thai & $29.6 \%$ & $25.8 \%$ \\
English & $11.9 \%$ & $19.9 \%$ \\
Punjabi & $17.7 \%$ & 29.45 \\
Thai-English & $23.5 \%$ & $9.5 \%$ \\
Thai-Punjabi & $11.5 \%$ & $9.2 \%$ \\
English-Punjabi & $1.3 \%$ & $1.6 \%$ \\
T-E-P & $4.4 \%$ & $4.6 \%$ \\
\hline & $\left(\chi^{2}=30.37, \mathrm{df}=6, \mathrm{p}<0.01\right)$
\end{tabular}

However, the dominant language of each gender is different. Females tend to use Punjabi the most while males prefer Thai. Females use Punjabi with elders in the family such as grandparents and parents while males use Thai almost equally among everyone in the family. The language used second most often among females is Thai, but among males the ThaiEnglish comes in second. Thai seems to be more comfortable for use by both genders when discussing general topics at dinner or personal matters with their family members. Males, in particular, also use Thai-English in those situations. Another significant finding is the use of single language vs. mixed language or code mixing in the family domain. Females use a single language such as Thai, Punjabi or English when conversing with their family members more than males. In contrast, the use of mixed languages: code mixing between Thai and English or Thai and Punjabi is higher among males than in females. The $\chi^{2}$ value indicates the significant relationship between language choice in family domain and gender.

\section{Family domain and age group}

As expected, the older age groups tend to use Punjabi, the ethnic language, more often than the younger age groups within the family domain. The age groups of 46-60 and over 60 use Punjabi the most at $31.1 \%$ and $69.0 \%$ respectively, while the age groups of 16-30 and 31-45 use Thai most often at $40.3 \%$ and $33.3 \%$. The younger age groups often use English, though not so among the older age groups. As for mixed languages, the older age groups tend to mix Thai with Punjabi more, while the younger age groups mix Thai with English more. Being the first or second generations in Thailand, acquiring national language is more important than any other language. This may reinforce the ability of language use in older age groups; that is, they are more fluent in Thai than English. (see Table 7). The $\chi^{2}$ value represents the significant relationship between language choice in family and age groups. Different age groups tend to have different patterns of language use. 
Table 7: Language choice by age in family domain

\begin{tabular}{|c|c|c|c|c|}
\hline Languages & $16-30$ & $31-45$ & $46-60$ & $>60$ \\
\hline Thai & $40.3 \%$ & $33.3 \%$ & $26.7 \%$ & $16.7 \%$ \\
\hline English & $0.6 \%$ & $26.7 \%$ & $12.4 \%$ & $1.2 \%$ \\
\hline Punjabi & $3.1 \%$ & $17.3 \%$ & $31.1 \%$ & $69 \%$ \\
\hline Thai-English & $31.4 \%$ & $1.3 \%$ & $9.9 \%$ & $0 \%$ \\
\hline Thai-Punjabi & $10.1 \%$ & $8 \%$ & $13.7 \%$ & $11.9 \%$ \\
\hline $\begin{array}{l}\text { English- } \\
\text { Punjabi }\end{array}$ & $10.1 \%$ & $4 \%$ & $0 \%$ & $1.2 \%$ \\
\hline T-E-P & $4.4 \%$ & $9.3 \%$ & $6.2 \%$ & $0 \%$ \\
\hline
\end{tabular}

\section{Family domain and educational level}

Table 8 shows that the higher one's education level, the less likely one is to use Punjabi in the family domain. People with a college or postgraduate degree tend to use Thai the most with their family members, whilst people with education levels of high school or lower use Punjabi the most. The language selected second most often is English for those with post-graduate degrees, Thai-English by college or bachelor degrees, and Thai by people with secondary school or lower education level. Chi Square is used to test if educational level has an influence on language in family domain. The result shows that there is a statistically significant relationship between language choice in family and educational level as the $\chi^{2}$ value is 240.94 at df 18 , obtaining a p-value less than 0.01 .
Table 8: Language choice by education in family domain

\begin{tabular}{lccc}
\hline Languages & Grade 1-12 & $\begin{array}{l}\text { College } \\
\text { \&Bachelor }\end{array}$ & Master \& PhD. \\
\hline Thai & $18.5 \%$ & $35.9 \%$ & $32.3 \%$ \\
English & $16.4 \%$ & $12.8 \%$ & $24.2 \%$ \\
Punjabi & $34.9 \%$ & $16.9 \%$ & $14.1 \%$ \\
Thai-English & $9.2 \%$ & $23.1 \%$ & $15.2 \%$ \\
Thai-Punjabi & $13 \%$ & $7.2 \%$ & $9.1 \%$ \\
English-Punjabi & $2.1 \%$ & $1 \%$ & $1 \%$ \\
T-E-P & $5.9 \%$ & $3.1 \%$ & $4 \%$ \\
\hline \multicolumn{4}{r}{$\left(\chi^{2}=240.94, \mathrm{df}=18, \mathrm{p}<0.01\right)$} \\
\hline
\end{tabular}

\section{Patterns of language choice in the friendship domain}

The 12-item questionnaire asked the respondents to indicate the language(s) used among friends. The topics of the talk were divided from general to personal matters and "friends" were segregated between ethnic vs. nonethnic friends. In general, the findings show that $35.7 \%$ of all the frequencies is Thai, followed by $30.7 \%$ English, and $17.5 \%$ Thai-English. The figures for Punjabi and Thai-Punjabi are similar; that is, $7.9 \%$ and $7.1 \%$ respectively. On the other hand, the use of Thai-English-Punjabi is only at $1.3 \%$ and $0.0 \%$ for English-Punjabi (referred to Table 2).

\section{Friendship domain and gender}

Similar to the family domain, the proportion of most commonly used language between males and females among friends are similar but the language choice is different (see Table 9). Males use Thai the most at $37.1 \%$, while females use English the most at $38.4 \%$. Comparing the use of each language by males versus females, the 
difference is significant. Thai is exceptional. The proportion of Thai used by males and females is slightly different. It is at $37.1 \%$ and $34.7 \%$ respectively. The use of English and Punjabi among females is two or more times greater than among males. In contrast, the use of mixed languages such as Thai-English, Thai-Punjabi or Thai-English and Punjabi among males is double or even triple that of females. As a ratio, the single language use to mixed languages use among friends is about 80:20 for females, while it is only 40:60 for males. Despite the ethnicity of their friends, the pattern of language choice is similar to that mentioned above (see Table 10). This shows a significant difference for males and females when it comes to patterns of language use in friend domain. Ethnicity of interlocutor has an effect on the language choice by gender in friend domain. A single language such as Thai and English is used more with non-ethnic friends by both genders; whereas, mixed language such as ThaiEnglish is used more with ethnic friends. The obvious finding show in Table 10 is that Punjabi is used only with ethnic friends.

The $\chi^{2}$ values were calculated to determine the relationship between language choice in friend domain and gender and the relationship between language choice in friend domain and friend's ethnicity. The results show that gender and friend's ethnicity are significantly related to language choice in friend domain.

\section{Friendship domain and age group}

Table 11 shows that the frequencies of Thai use among all age groups are about the same, between $34 \%$ and $39 \%$.
In contrast with the family domain, the older age groups use Thai with their friends more, while the younger age groups use English more. Table 12 shows that older age groups, especially those who are older than 60 use Punjabi more with their ethnic friends and Thai with their non-ethnic friends. Punjabi can also be found while conversing with the same ethnic friends in the age groups of 46-60. In contrast to the older age groups, the age groups 16-30 and $31-45$ do not use Punjabi at all or less than $1 \%$ regardless of their friends' ethnicity. Hence, the older age groups use Punjabi and/or Thai-Punjabi with their ethnic friends much more commonly than the younger age groups. Overall, the languages used in the age groups 16-30 and 31-45 include Thai, English, and Thai-English mix while speaking to both ethnic and nonethnic friends. On the other hand, the older age groups 46-60 and over 60 speak Thai, English, Punjabi, and ThaiPunjabi more with their ethnic friends and Thai, English and Thai-English more with non-ethnic friends (see Table 12). The $\chi^{2}$ values show statistically significant relationships between language choice in friend domain and age groups; and language choice in friend domain and friend's ethnicity. 
Table 9: Language choice by gender in friend domain

\begin{tabular}{lcc}
\multicolumn{1}{c}{ Languages } & Male & Female \\
\hline Thai & $37.1 \%$ & $34.7 \%$ \\
English & $19.1 \%$ & $38.4 \%$ \\
Punjabi & $3.9 \%$ & $10.5 \%$ \\
Thai-English & $27.7 \%$ & $10.5 \%$ \\
Thai-Punjabi & $9.8 \%$ & 5.35 \\
English-Punjabi & $0 \%$ & $0 \%$ \\
T-E-P & $2.3 \%$ & $0.5 \%$ \\
\hline & $\left(\chi^{2}=60.57, \mathrm{df}=12, \mathrm{p}<0.01\right)$
\end{tabular}

Table 10: Language choice by gender and ethnicity in friend domain

\begin{tabular}{lcccc}
\hline Languages & \multicolumn{2}{c}{ Male } & \multicolumn{2}{c}{ Female } \\
\hline & E & N & E & N \\
Thai & 33.9 & 40.3 & 28.1 & 42 \\
English & 12.6 & 25.6 & 34.2 & 43.1 \\
Punjabi & 7.9 & 0 & 19.6 & 0.6 \\
Thai-English & 30.7 & 24.8 & 11.6 & 9.4 \\
Thai-Punjabi & 10.2 & 9.3 & 6.5 & 3.9 \\
English- & 0 & 0 & 0 & 0 \\
Punjabi & 0 & 0 & 0 & 1.1 \\
T-E-P & 4.7 & 0 &
\end{tabular}

$\mathrm{E}=$ Ethnic friend $\mathrm{N}=$ Non-ethnic friend $\left(\chi^{2}=125.46, \mathrm{df}=12, \mathrm{p}<0.01\right)$
Table 11: Language choice by age in friend domain

\begin{tabular}{lcccc}
\hline Languages & $16-30$ & $31-45$ & $46-60$ & $>60$ \\
\hline Thai & 34.6 & 35.1 & 36.0 & 38.5 \\
English & 34.6 & 47.4 & 24.1 & 14.3 \\
Punjabi & 0 & 0 & 10.8 & 30.8 \\
Thai-English & 29.8 & 17.5 & 11.3 & 0 \\
Thai-Punjabi & 0 & 0 & 14.8 & 16.5 \\
English- & 0 & 0 & 0 & 0 \\
Punjabi & 0 & 0 & 3 & 0 \\
T-E-P & 0.9 & 0 & \\
\hline \multicolumn{5}{l}{$\left(\chi^{2}=206.26, \mathrm{df}=12, \mathrm{p}<0.01\right)$}
\end{tabular}

Table 12: Language choice by age and ethnicity in friend domain

\begin{tabular}{|c|c|c|c|c|c|c|c|c|}
\hline \multirow[t]{2}{*}{ Lang } & \multicolumn{2}{|c|}{$16-30$} & \multicolumn{2}{|c|}{$31-45$} & \multicolumn{2}{|c|}{$46-60$} & \multicolumn{2}{|c|}{$>60$} \\
\hline & $\mathbf{E}$ & $\mathbf{N}$ & E & $\mathbf{N}$ & $\mathbf{E}$ & $\mathbf{N}$ & $\mathbf{E}$ & $\mathbf{N}$ \\
\hline Thai & 35.3 & 33.9 & 39.0 & 30.9 & 26.4 & 46.4 & 13.6 & 61.7 \\
\hline English & 28.6 & 41.3 & 40.7 & 54.5 & 23.6 & 24.7 & 2.3 & 25.5 \\
\hline Punjabi & 0 & 0 & 0 & 0 & 19.8 & 1.0 & 63.6 & 0 \\
\hline $\begin{array}{l}\text { Thai- } \\
\text { English }\end{array}$ & 34.5 & 24.8 & 20.3 & 14.5 & 8.5 & 14.4 & 0 & 0 \\
\hline $\begin{array}{l}\text { Thai- } \\
\text { Punjabi }\end{array}$ & 0 & 0 & 0 & 0 & 16 & 13.4 & 20.5 & 12.8 \\
\hline $\begin{array}{l}\text { English- } \\
\text { Punjabi }\end{array}$ & 0 & 0 & 0 & 0 & 0 & 0 & 0 & 0 \\
\hline T-E-P & 1.7 & 0 & 0 & 0 & 5.7 & 0 & 0 & 0 \\
\hline & thn & $\begin{array}{l}\text { c fri } \\
(\chi\end{array}$ & $\begin{array}{l}\text { and } \\
=1\end{array}$ & $\begin{array}{l}\mathrm{N}= \\
7.45\end{array}$ & $\begin{array}{l}\text { Nor } \\
\text { df }\end{array}$ & $\begin{array}{l}\text {-ethi } \\
=12,\end{array}$ & $\begin{array}{l}\text { ic fr } \\
p<0\end{array}$ & $\begin{array}{l}\text { end } \\
.01)\end{array}$ \\
\hline
\end{tabular}




\section{Friendship domain and educational level}

Similar to the family domain, education level is inversely related to the use of ethnic language. That is, the higher the education level, the less the use of the ethnic language. Table 13 shows that people with a higher education levels use less Punjabi and more Thai and English than those with lower educational levels. The very slight or nil use of Punjabi in the friend domain by people of the highest education levels confirms the inverse relationship between education level and ethnic language use. The $\chi^{2}$ value indicates a significant relationship between language choice in friend domain and educational level.

Table 13: Language choice by education in friend domain

\begin{tabular}{lccc}
\hline Languages & Grade 1-12 & $\begin{array}{l}\text { College } \\
\text { \&Bachelor }\end{array}$ & Master \& PhD. \\
\hline Thai & 30.7 & 35.3 & 50.5 \\
English & 26.8 & 31.8 & 38.6 \\
Punjabi & 15.7 & 2.4 & 0 \\
Thai-English & 13.2 & 25.1 & 9.9 \\
Thai-Punjabi & 11.4 & 4.7 & 1.0 \\
English-Punjabi & 0 & 0 & 0 \\
T-E-P & 2.1 & 0.8 & 0 \\
\hline & $\left(\chi^{2}=84.41, \mathrm{df}=8, \mathrm{p}<0.01\right)$
\end{tabular}

\section{Patterns of language choice in the work domain}

Prior to looking at the results of the patterns of language choice in work domain by age group, an explanation about the number of the respondents who filled this part is in order. Because some of the respondents are students, housewives and retired, there were only eight respondents out of 14 from the age group of 16-30, four out 6 from the age group of $31-45$, ten out of 13 from the age group of 46-60 and three out of 7 from the age group of above 60 . The frequencies reported here are from working people.

The respondents were asked to determine what language(s) they use with their boss, colleagues, and staff when conversing on general topics and discussing about important documents. Altogether there were nine scenarios in this section. The findings show that Thai is most commonly used in this domain, followed by English, and ThaiEnglish with percentages of $46.1 \%$, $26.7 \%$ and $14 \%$ respectively (referred to Table 2). This is likely because the work environment is made up of a greater number of native Thais with some foreign bosses or colleagues. Punjabi also appears to be used in this domain. The reason could be that there may be ethnic Indians or even family members present as colleagues in the workplace. As most of the Thai Sikh community is engaged in their own family business, this may not be surprising.

\section{Work domain and gender}

The results show that both males and females use Thai the most in the work domain at $44.2 \%$ and $46.6 \%$. English is the second most commonly used language by both genders, followed by Thai-English. However, males share similar frequencies of use between English (18.6\%) and Thai-English $(17.1 \%)$, while females use English at $37.3 \%$ that is almost four times that of Thai-English, which is $10.2 \%$. It can be seen that Punjabi is used more by males than females in the work environment 
although the difference is not significant. Similar to patterns of language use in the family and friendship domains, females tend to use a single language more commonly than males (see Table 14).

To test if there is a significant relationship between language choice in work domain and gender, $\chi^{2}$ value is calculated. The result supports the significance of this relationship as the $\chi^{2}$ value is 20.08 for $\mathrm{df}=4$, obtaining a p-value less than 0.01 .

Table 14: Language choice by gender in work domain

\begin{tabular}{lcc}
\multicolumn{1}{c}{ Languages } & Male & Female \\
\hline Thai & 44.2 & 46.6 \\
English & 18.6 & 37.3 \\
Punjabi & 4.7 & 2.5 \\
Thai-English & 17.1 & 10.2 \\
Thai-Punjabi & 5.4 & 3.4 \\
English-Punjabi & 0.0 & 0 \\
T-E-P & 10.1 & 0 \\
\hline & $\left(\chi^{2}=20.08, \mathrm{df}=4, \mathrm{p}<0.01\right)$
\end{tabular}

\section{Work domain and age group}

Table 15 shows that people in the age groups 31-45 and older use Thai the most in the work domain, while the age groups 16-30 use English the most. It is noticeable that Thai is most often used in the age group 46-60 at 57.3\%, followed by the age group over 60 at $47.4 \%$, then the age group $31-45$ at $40.4 \%$, and then the age group 16-30 at $36.5 \%$. This can be interpreted that people in the older age groups are well established in networking with native Thais and/or their career has closer ties to native Thais. In contrast to Thai, there is an inverse relationship between the use of English and the age group. English is used more by people in the younger age groups and less or not at all by people in the older age groups. The younger age groups use Thai and English in almost the same proportion in the work domain, though English is a slightly higher. This may indicate that younger people work not only with Thai companies but also with international corporations. The number of respondents using Punjabi in the work domain is small. People over 60 use it the most, either as a single language or mixed with other languages. They may be surrounded not only with Thai colleagues or workers but also the same ethnic staff or ethnic family members at the workplace.

To test if there is an association between language choice in work domain and age groups, the $\chi^{2}$ value is calculated and the result shows a significant relationship between them.

Table 15: Language choice by age in work domain

\begin{tabular}{lcccc} 
Languages & $16-30$ & $31-45$ & $46-60$ & $>60$ \\
\hline Thai & 36.5 & 40.4 & 57.3 & 47.4 \\
English & 39.2 & 34.0 & 24.4 & 0 \\
Punjabi & 0.0 & 4.3 & 1.2 & 13.2 \\
Thai-English & 20.3 & 21.3 & 11.0 & 0 \\
Thai-Punjabi & 0 & 0 & 4.9 & 15.8 \\
English- & 0 & 0 & 0 & 0 \\
Punjabi & 4.1 & 0 & 1.2 & 23.7 \\
\hline T-E-P & $\left(\chi^{2}=87.38, \mathrm{df}=12, \mathrm{p}<0.01\right)$ \\
\hline \multicolumn{5}{l}{}
\end{tabular}




\section{Work domain and educational Level}

The respondents in each group of educational level use Thai the most in the work domain. People with postgraduate degrees use either Thai or English at their workplace, while others show a more varied choice of languages. This can be interpreted that respondents with higher education tend to work in particular professions, which require using Thai and/or English as medium of communication. While respondents with lower education are more involved in family or small business, more choices of language are available at their workplace. For example, when the respondents of this group converse with their partner or worker of the same ethnicity, apart from using Thai and English, they use Punjabi or code mixing of Thai with other languages. The pattern of language choice in the work domain is similar to the family and friend domain as far as the ethnic language is concerned. That is, the higher the educational level, the lower the use of ethnic language in the domain. Punjabi is not used at all by people with postgraduate degrees, while it is most often used by respondents with a high school educated or lower. By way of contrast, the pattern of Thai use appears not to be related to one's education level. The respondents with college or bachelors degree use Thai less compared to other education levels. This may be because this group uses Thai-English more than the other two groups (see Table 16). The $\chi^{2}$ value indicates that the relationship between language choice in work domain and educational level is significant.
Table 16: Language choice by education in work domain

\begin{tabular}{lccc}
\hline Languages & Grade 1-12 & $\begin{array}{l}\text { College } \\
\text { \&Bachelor }\end{array}$ & Master \& PhD. \\
\hline Thai & 43.2 & 36.6 & 62.3 \\
English & 12.3 & 31.2 & 37.7 \\
Punjabi & 8.6 & 2.2 & 0 \\
Thai-English & 11.1 & 26.9 & 0 \\
Thai-Punjabi & 12.3 & 0 & 0 \\
English-Punjabi & 0 & 0 & 0 \\
T-E-P & 12.3 & 3.2 & 0 \\
\hline \multicolumn{4}{r}{$\left(\chi^{2}=75.84, \mathrm{df}=8, \mathrm{p}<0.01\right)$}
\end{tabular}

\section{Patterns of language choice in the temple domain}

The respondents were asked to indicate the language(s) they use in general with the priests, ethnic community members, and non-community members at the Sikh temple. Moreover, the respondents also had to state the language(s) they use when discussing religious events and ceremonies with the temple priest, discussing such matters with other community members, and when providing information about the Sikh temple to visitors from a non-Sikh community. Referred to Table 2 , it shows that the language most often used in the temple domain is Punjabi at nearly $40 \%$, followed by English at $22.1 \%$, and then Thai at $12.8 \%$. Punjabi is undoubtedly the dominant language in the temple domain as Punjabi is used in reading Guru Granth Sahib (the most sacred scriptures of the Sikh religion), singing hymns, and sermons at the temple. Mixed languages among Thai, English, and Punjabi are also found at the Sikh temple. The figure for the mixed languages used in temple domain is approximately one fourth of all the frequencies. The mixing appears 
to come from the younger generations who must communicate with priests or community leaders with as much Punjabi as possible, but are not comfortable enough to use it exclusively and so must use both English and Punjabi, depending on the language the listener may understand. So, for example, with the priest the mix is PunjabiEnglish, since most priests are not able to speak Thai; with community leaders at the temple Punjabi is mixed with either English or Thai, since most community members, being of the older age group, can also understand English and speak Thai fluently.

\section{Temple domain and gender}

In the temple domain, there is almost no difference in language use patterns between males and females. (see Table 17). Although females employ Punjabi more than males, Punjabi is still used the most at the temple among males. Hence, Punjabi is the dominant language at the Sikh temple. To test if there is an association between language choice in temple domain and gender, the $\chi^{2}$ value is calculated and the result shows that there is no significant relationship between them.

Table 17: Language choice by gender in temple domain

\begin{tabular}{lcc}
\multicolumn{1}{c}{ Languages } & Male & Female \\
\hline Thai & 12.6 & 12.8 \\
English & 21.8 & 22.3 \\
Punjabi & 33.6 & 43 \\
Thai-English & 12.6 & 6.1 \\
Thai-Punjabi & 3.4 & 3.9 \\
English-Punjabi & 8.4 & 6.7 \\
T-E-P & 7.6 & 5 \\
\hline & $\left.\chi^{2}=5.61, \mathrm{df}=4, \mathrm{p}>0.01\right)$
\end{tabular}

\section{Temple domain and age group}

Table 18 shows that Punjabi is the language most often used among almost all the age groups. The youngest age group uses English the most. There is a significant difference in the use of Punjabi among the older age groups when compared to the younger. The respondents in the age group of over 60 speak Punjabi the most, while the respondents in the youngest age group use it the least. In contrast, the use of English is most common in the younger age groups and less in the older age groups. The significant finding suggests that there is a shift occurring from Punjabi $(74.4 \%$ among the oldest cohort; only $21.6 \%$ among the youngest) to English (34.2\% among the youngest cohort; only $4.7 \%$ among the oldest.) The percentage of use of Thai is not significant in the temple domain. However, the slight difference across all age groups shows that Thai use gradually increases with the age groups. This may be from the fluency of each age group in Thai and English as, for example, the older age groups interact with Thai natives more and people of the younger group speak better English due to their education in international schools. The $\chi^{2}$ value indicates that the relationship between language choice in temple domain and age groups is significant. 
Table 18: Language choice by age in temple domain

\begin{tabular}{lcccc}
\hline Languages & $16-30$ & $31-45$ & $46-60$ & $>60$ \\
\hline Thai & 9.9 & 13.3 & 15.5 & 14.0 \\
\hline English & 34.2 & 20.0 & 17.5 & 4.7 \\
Punjabi & 21.6 & 26.7 & 50.5 & 74.4 \\
Thai-English & 12.6 & 17.8 & 2.1 & 4.7 \\
Thai-Punjabi & 1.8 & 0 & 8.2 & 2.3 \\
\hline English- & 11.7 & 8.9 & 3.1 & 0 \\
Punjabi & 8.1 & 13.3 & 3.1 & 0 \\
\hline T-E-P & \multicolumn{5}{r}{$\left.\chi^{2}=62.54, \mathrm{df}=12, \mathrm{p}<0.01\right)$} \\
\hline
\end{tabular}

\section{Temple domain and educational level}

Punjabi is used the most in temple domain, regardless of educational level. The finding reveals that there is no relationship between the educational level and the ethnic language. It can be seen from Table 19 that people with college or bachelor degree and higher use Punjabi in a similar proportion of about $36 \%$ in this domain. Moreover, the patterns of other choices of language in the temple domain are in neither direct nor inverse relationship with education level. As for English, the higher the education level, the more the use of English in this domain. Chi Square is tested and its value of 16.7 is obtained for df 8 , showing a p-value is more than 0.01 . Thus, the relationship between language choice in temple domain and educational level is insignificant.
Table 19: Language choice by education in temple domain

\begin{tabular}{lccc}
\hline Languages & Grade 1-12 & $\begin{array}{l}\text { College } \\
\text { \&Bachelor }\end{array}$ & Master \& PhD, \\
\hline Thai & 13.2 & 9.73 & 17.2 \\
\hline English & 19.0 & 20.35 & 31.3 \\
Punjabi & 44.6 & 35.40 & 35.9 \\
\hline Thai-English & 6.6 & 15.04 & 1.6 \\
Thai-Punjabi & 2.5 & 6.19 & 1.6 \\
English-Punjabi & 5.8 & 8.85 & 7.8 \\
T-E-P & 8.3 & 4.42 & 4.7 \\
\hline \multicolumn{4}{c}{$=16.7$, df $8, \mathrm{p}>0.01)$} \\
\end{tabular}

Patterns of language choice in the school domain

The respondents were asked to indicate the language(s) they use or used to use at school when conversing with teachers and classmates on general issues, on formal issues, and on informal issues. Referred to Table 2, it shows that English is used the most in the school domain at $47.4 \%$, followed by Thai-English at $21.6 \%$, then Thai at $17.2 \%$ and lastly Punjabi at $13.8 \%$. There is nil response for the other mixed languages. This pattern of language choice is likely attributed to the fact that Thai-Sikhs attend Englishmedium schools more commonly than local Thai schools. This can be seen from the number of responses for English and Thai-English, compared to Thai. Punjabi is also selected as the language used in the school domain. It is the language that the respondents of the older generation used to use when they attended a school in India or the Thai-Sikh evening school, once operated by the Sikh temple in Bangkok, where Punjabi was used as a medium of communication. 


\section{School domain and gender}

Looking at the figure in Table 20, both males and females use English the most in the school domain at the proportion of $44 \%$ and $66 \%$ respectively. Among males, the use of Thai and Thai-English is almost at the same amount, at $22 \%$ and $21 \%$ respectively. The language used the least often at schools for males is Punjabi at $10 \%$. Among females, Thai-English (29\%) is the second most commonly used language, followed by Punjabi (22\%) and then Thai (18\%). This shows that females tend to use less Thai when compared to males. The pattern of language choice between males and females at school are quite similar. The only noticeable difference is that females use Punjabi more at schools than do males.

To understand the pattern of language choice in school domain better, the Chi Square is tested and its value of 4.48 is obtained for df 3 , showing a p-value is more than 0.01 . This suggests that the relationship between language choice in school domain and gender is insignificant.

Table 20: Language choice by gender in school domain

\begin{tabular}{lcc}
\hline \multicolumn{1}{c}{ Languages } & Male & Female \\
\hline Thai & 22 & 18 \\
English & 44 & 66 \\
Punjabi & 10 & 22 \\
Thai-English & 21 & 29 \\
Thai-Punjabi & 0 & 0 \\
English-Punjabi & 0 & 0 \\
T-E-P & 0 & 0 \\
\hline \multicolumn{2}{c}{$\left.\chi^{2}=4.48, \mathrm{df}=3, \mathrm{p}>0.01\right)$} &
\end{tabular}

\section{School domain and age group}

Table 21 presents English as the language most often used among almost all age groups, while Punjabi is used the most by people who are above 60 . The patterns of language choice of respondents at 16-30 and 31-45 are the same. That is they use English the most at school, followed by Thai-English, and then Thai. Punjabi is not used at all. The respondents in age group 46-60 use English the most also, followed by Punjabi, Thai-English, and Thai. This is the only group that uses four languages in the school setting. The oldest age group, namely the above 60 group, use Punjabi the most at schools with the figure at $50 \%$. This significant finding shows that they could be the first generation who were educated from a Punjabi-medium school in India, or the Thai-Sikh Evening school once operated by the Thai-Sikh temple here in Bangkok. The Chi square is calculated to determine the relationship between language choice in school domain and age groups. The result shows that the $\chi^{2}$ value indicates significant relationship between them.

Table 21: Language choice by age in school domain

\begin{tabular}{lcccc} 
Languages & $16-30$ & $31-45$ & $46-60$ & $>60$ \\
\hline Thai & 21.1 & 16.2 & 9.1 & 23.5 \\
English & 46.3 & 62.2 & 51.5 & 26.5 \\
Punjabi & 0.0 & 0.0 & 22.7 & 50 \\
Thai-English & 32.6 & 21.6 & 16.7 & 0 \\
Thai-Punjabi & 0 & 0 & 0 & 0 \\
English- & 0 & 0 & 0 & 0 \\
Punjabi & 0 & 0 & 0 & 0 \\
T-E-P & $\left(\chi^{2}=77.57, \mathrm{df}=9, \mathrm{p}<0.01\right)$ & \\
\hline \multicolumn{5}{r}{}
\end{tabular}




\section{School domain and educational level}

Table 22 shows that English is used the most among all education levels. A difference appears in the patterns of other language choices in each level. The respondents with a higher education level use English and Thai more than Punjabi. The respondents with post-graduate degrees use English the most at $55.8 \%$, followed by Thai at $27.9 \%$, and then Thai-English at $16.3 \%$. This can be interpreted that the institutes that the respondents attend or used to attend use English or Thai as the medium of instructions. Or else, they were educated or they are now studying abroad in English medium schools. The patterns of language choice of the respondents with college or bachelor degree are almost the same as the highest education level. However, Punjabi also exists in a small proportion within this group. They use Punjabi not with their teachers but friends when they talk about informal topics such as discussing a dining venue. Apart from using English the most, the respondents with high school education or lower use Punjabi as the second most commonly used language use at school, followed by ThaiEnglish, and the Thai. The use of the Punjabi is one fourth of all the responses in this level. Comparing across all educational level, the respondents with educational level of high school or lower use Punjabi the most. They are mostly the first generation in Thailand, and they received education from both schools in India and Thai-Sikh schools in Thailand. Hence, during their school days, they conversed with their teachers and friends in Punjabi on both formal and informal topics. Nonetheless, there is a significant relationship between language choice in school domain and educational level as the $\chi^{2}$ value of 31.62 is obtained for df 6 , showing a p-value is less than 0.01

Table 22: Language choice by education in school domain

\begin{tabular}{lccc} 
Languages & Grade 1-12 & $\begin{array}{l}\text { College } \\
\text { \&Bachelor }\end{array}$ & Master \& PhD. \\
\hline Thai & 10.8 & 19.5 & 27.9 \\
English & 45.1 & 46.0 & 55.8 \\
Punjabi & 26.5 & 5.7 & 0 \\
Thai-English & 17.6 & 28.7 & 16.3 \\
Thai-Punjabi & 0 & 0 & 0 \\
English-Punjabi & 0 & 0 & 0 \\
T-E-P & 0 & 0 & 0 \\
\hline \multicolumn{4}{r}{$\left(\chi^{2}=31.62, \mathrm{df}=6, \mathrm{p}<0.01\right)$}
\end{tabular}

\section{Patterns of language choice in the market domain}

The 10-item questionnaire in this part related to interlocutors and location of the markets. The interlocutors are seller and the person who the respondents go shopping with who are of the same and different ethnicity. The locations are the Sikh-oriented market and other markets. Sikh-oriented market is located in Pahurat, a district known as "little India," similar to such areas in other cities throughout Southeast Asia. The respondents had to specify the language(s) they used in general and on specific topics such as having a small talk with a seller, bargaining with a seller and commenting on product with their companion(s) when they shop in the Sikh-oriented market and other markets. The results show that Thai is generally used to the most in the market domain at $33.1 \%$, followed by 
the similar proportion of Thai-English at $17.1 \%$, English at $15.6 \%$, Punjabi at $15.8 \%$, and other mixed languages such as Thai-Punjabi at $8.6 \%$, Thai-EnglishPunjabi at $7.4 \%$ and English-Punjabi at $2.4 \%$ (referred to Table 2). Apart from Family and Temple domain, Market is another domain in which EnglishPunjabi is used, although to a very small degree. The reason for using Punjabi mixed with other languages is due to the ethnicity of the seller and the shopping companions. If the seller and/or the shopping companion are of the same ethnicity, and the respondents are able to use Punjabi, hence there are more choices to select when conversing. Another reason mentioned during the interview is that the respondents used Punjabi mixed with other languages with their companion as a code of language when commenting about products; hence people surrounding would not understand.

\section{Market domain and gender}

The patterns of language choice within the market domain among males and females are very similar. Thai is used the most by both genders in the market domain, and other languages are used in similar patterns (Table 22). The obvious differences are in the use of Punjabi and Thai-English. Females use Punjabi more than males, while males use Thai-English much more than females. The reason is that in the Sikhoriented market females converse in Punjabi the most followed by Thai, while males use Thai the most and followed by Thai Punjabi (Table 23). That means females tend to speak Punjabi with sellers if they are the same ethnic and/or with their companion(s) when they go shopping in Sikhoriented market. In other markets, Thai is used the most by males and females. It is obvious because there are more local people in other markets; hence Thai is essential.

To explain the relationship between language choice in market domain and gender and language choice in market domain with gender and location of the market. The results of both $\chi^{2}$ value are 40.06 at $\mathrm{df} 4$ and 92.63 at $\mathrm{df} 12$ showing a p-value is less than 0.01 . This indicates that there is a significant relationship between language choice in market domain and gender and language choice in market domain with gender and location of the market. 
Table 22: Language choice by gender in market domain

\begin{tabular}{lcc}
\multicolumn{1}{c}{ Languages } & Male & Female \\
\hline Thai & 33.9 & 32.5 \\
English & 11.0 & 18.7 \\
Punjabi & 7.8 & 21.2 \\
Thai-English & 26.6 & 10.7 \\
Thai-Punjabi & 8.7 & 8.6 \\
English-Punjabi & 2.8 & 2.1 \\
T-E-P & 9.2 & 6.1 \\
\hline \multicolumn{4}{r}{$\left(\chi^{2}=40.06, \mathrm{df}=4, \mathrm{p}<0.01\right)$}
\end{tabular}

Table 23: Language choice by gender and market location in market domain

\begin{tabular}{lcccc} 
Languages & \multicolumn{2}{c}{ Male } & \multicolumn{2}{c}{ Female } \\
\hline \multirow{2}{*}{ Thai } & $\mathbf{S}$ & $\mathbf{O}$ & $\mathrm{S}$ & $\mathbf{O}$ \\
English & 25.2 & 43.0 & 23.9 & 43.2 \\
Punjabi & 9.9 & 12.1 & 17.8 & 19.9 \\
Thai-English & 12.6 & 2.8 & 28.9 & 11.6 \\
Thai-Punjabi & 22.5 & 30.8 & 7.8 & 14.4 \\
English- & 12.6 & 4.7 & 11.7 & 4.8 \\
Punjabi & 4.5 & 0.9 & 2.8 & 1.4 \\
T-E-P & 12.6 & 5.6 & 7.2 & 4.8 \\
\hline \multicolumn{4}{r}{$\mathrm{S}=$ Sikh-oriented market } & $\mathrm{O}=$ Other markets \\
& \multicolumn{5}{c}{$\left(\chi^{2}=92.63, \mathrm{df}=12, \mathrm{p}<0.01\right)$} \\
\hline
\end{tabular}

Table 24: Language choice by age in market domain

\begin{tabular}{lcccc}
\hline Languages & $16-30$ & $31-45$ & $46-60$ & $>60$ \\
\hline Thai & 32.3 & 24.4 & 33.3 & 41.1 \\
English & 18.0 & 25.6 & 12.3 & 8.4 \\
Punjabi & 4.8 & 14.0 & 20.4 & 29.9 \\
Thai-English & 30.7 & 19.8 & 6.8 & 6.5 \\
Thai-Punjabi & 5.3 & 7.0 & 9.9 & 14.0 \\
English- & 3.7 & 5.8 & 0.6 & 0 \\
Punjabi & 5.3 & 3.5 & 16.7 & 0 \\
T-E-P & \multicolumn{4}{l}{$\chi^{2}=92.9$, df $\left.12, \mathrm{p}<0.01\right)$} \\
\hline
\end{tabular}

Table 25: Language choice by age and market location in market domain

\begin{tabular}{lcccccccc}
\hline Lang & \multicolumn{2}{c}{$16-30$} & \multicolumn{2}{c}{$31-45$} & \multicolumn{2}{c}{$46-60$} & \multicolumn{2}{c}{$>60$} \\
\hline Thai & $\mathbf{S}$ & $\mathbf{O}$ & $\mathbf{S}$ & $\mathbf{O}$ & $\mathbf{S}$ & $\mathbf{O}$ & $\mathbf{S}$ & $\mathbf{O}$ \\
& 23.5 & 41.8 & 10.6 & 41.0 & 33.7 & 32.8 & 34.4 & 50.0 \\
English & 17.3 & 18.7 & 23.4 & 28.2 & 10.5 & 14.9 & 8.2 & 8.7 \\
\hline Punjabi & 6.1 & 3.3 & 25.5 & 0.0 & 27.4 & 10.4 & 36.1 & 21.7 \\
$\begin{array}{l}\text { Thai- } \\
\text { English }\end{array}$ & 27.6 & 34.1 & 14.9 & 25.6 & 0 & 16.4 & 8.2 & 4.3 \\
$\begin{array}{l}\text { Thai- } \\
\text { Punjabi }\end{array}$ & 10.2 & 0 & 12.8 & 0 & 11.6 & 7.5 & 13.1 & 15.2 \\
$\begin{array}{l}\text { English- } \\
\text { Punjabi }\end{array}$ & 5.1 & 2.2 & 10.6 & 0 & 0 & 1.5 & 0 & 0 \\
\hline T-E-P & 10.2 & 0 & 2.1 & 5.1 & 16.8 & 16.4 & 0 & 0 \\
\hline & $\mathrm{S}=$ Sikh-oriented market & $\mathrm{O}=$ Other markets \\
& \multicolumn{7}{c}{$\left.\chi^{2}=154.03, \mathrm{df} 28, \mathrm{p}<0.01\right)$} \\
\hline
\end{tabular}

\section{Market domain and age groups}

In three of the four age groups, Thai is used the most in the market domain. Among those respondents aged 31 to 45, English is used more (see Table 24). Beyond that, the patterns of language choice in market domain are rather different for each age group. The respondents in the youngest age group, 16-30, used Thai the most at $32.3 \%$, followed by Thai-English at $30.7 \%$, English at $18 \%$ and at approximate proportion of $4.5 \%$ each in Punjabi, Thai-Punjabi, English-Punjabi and The-English-Punjabi. Next, the respondents in the age group of 31-45 employ English and Thai in the market domain in similar proportion at $25.6 \%$ and $24.4 \%$ respectively. Apart from 
that, Thai-English is used at $19.8 \%$, followed by Punjabi at $14 \%$ and mixing language of Punjabi with others are used at $15.8 \%$. The respondents in the age group of 46-60 and above 60 use Thai the most and followed by Punjabi. The difference in patterns of language choices between these two groups is that the use of English only or English mixed with Punjabi or Punjabi and Thai are used lesser or not at all in the oldest age group. To explain if there is an association between language choice in market domain and age groups, the $\chi^{2}$ value of 92.9 is obtained for df 12 , showing a p-value is less than 0.01 . This indicates that the relationship between language choice in market domain and age groups is strong.

To understand the patterns of language choice in the market domain clearer, it is necessary to distinguish between Sikh-oriented markets and other types of markets. All age groups use Thai the most in non-Sikh-oriented markets, while language use varies in Sikhoriented market (see Table 25). The language used most in Sikh-oriented market is Thai-English for the age group of 16-30, Thai for the age group of 46-60 and Punjabi for the age group of 31-45 and above 60 .

There are significant patterns of language choice found in the market domain. First, there is a reverse relationship between ages and the use of Punjabi. The younger the age group, the less the respondents use Punjabi. Second, location of the market has an influence on the use of Punjabi. Punjabi is used more in Sikh-oriented market than in other markets. This statement is supported by the $\chi^{2}$ value of 154.03 for df 28 , obtaining a p-value less than 0.01 . This indicates that there is a significant relationship between language choice in market domain with age group and location of the market.

\section{Market domain and educational level}

Table 26 shows that Thai is used the most in the market domain regardless the respondents' educational levels. Certain noticeable patterns of language choice in market domain are found. The first one is that the higher the educational level, the more the use of Thai and/or English. Second, the lower the educational level, the higher the use of Punjabi in the market domain. English is used at almost the same level by all educational level. However, there is a significant relationship between language choice in market domain and educational level as the $\chi^{2}$ value of 48.29 is obtained for $\mathrm{df} 8$, showing a $\mathrm{p}$ value is less than 0.01 .

Table 26: Language choice by education in market domain

\begin{tabular}{lccc}
\hline Languages & Grade 1-12 & $\begin{array}{l}\text { College } \\
\text { \&Bachelor }\end{array}$ & Master \& PhD. \\
\hline Thai & 31.2 & 26.7 & 51.6 \\
English & 16.2 & 14.4 & 16.8 \\
Punjabi & 20.2 & 16.3 & 3.2 \\
Thai--English & 9.7 & 25.7 & 17.9 \\
Thai-Punjabi & 9.7 & 7.9 & 7.4 \\
English-Punjabi & 0.4 & 5.9 & 0.0 \\
T-E-P & 12.6 & 3.0 & 3.2 \\
\hline \multicolumn{4}{r}{$\left(\chi^{2}=48.29\right.$, df $\left.8, \mathrm{p}<0.01\right)$}
\end{tabular}


Table 27: Summary

\begin{tabular}{|c|c|c|c|c|c|}
\hline FAMILY & FRIEND & WORK & TEMPLE & SCHOOL & MARKET \\
\hline Thai & Thai & Thai & Punjabi & English & Thai \\
\hline Punjabi & English & English & English & Thai-English & Thai-English \\
\hline Thai-English & Thai-English & Thai-English & Thai & Thai & English,Punjabi \\
\hline$\uparrow$ & $\uparrow$ & 个 & $\uparrow$ & $\uparrow$ & $\uparrow$ \\
\hline \multicolumn{6}{|c|}{ Social variables influencing choices of language in each domain } \\
\hline Gender & Gender & Gender & Age & Age & Gender \\
\hline Age & Age & Age & & Education & Age \\
\hline \multirow[t]{2}{*}{ Education } & Education & Education & & & Education \\
\hline & Ethnicity & & & & Location \\
\hline
\end{tabular}

\section{Summary}

The patterns of language choice in Thai-Sikh community vary according to domains. Although Thai is a dominant language in the community, it is not in all the domains. In general, Thai is used the most in family, friendship, work and market domains, while Punjabi in temple domain and English in school domain. Domain is not the only factor that determines the choice of language but also the speaker's social characteristics. The inferential statistics suggest that gender, age and educational level have an influence on the language choice in certain domains such as family, friendship, work and market. In school domain, the variables that influence the language choice are age and educational level; while in temple domain, age is the only variable that affects the choice of language. In addition, the ethnicity of the interlocutor and location of the conversation also affect the patterns of language choice in friendship and market domain in regarding with gender and age. Table 27 shows the most three languages used and the social factors affecting the language choice in each domain.

\section{Conclusion}

It can be seen that the Thai-Sikh community is multilingual. Languages of their choice are not only Thai and Punjabi, but also English and code mixing among Thai, English and Punjabi. From six domains, Thai dominates in four domains namely family, friend, work and market domains, while English in school domain and Punjabi is temple domain. Surprisingly, Thai is used most in the family domain, an intimate domain in which the ethnic language is expected to be used the most. Punjabi dominates in only one domain and it is used less frequent or not used at all compared to other languages in other domains. This suggests a decline in the use of Punjabi in the community and if the decline continues, Punjabi may be replaced by Thai or English in the future. To 
comprehend the patterns of language choice among Thai-Sikh people better and to predict if Punjabi will survive in the community, other Thai-Sikh people from different location in Bangkok or other parts of Thailand should be taken into the account. Moreover, other variables such as attitude, language proficiency, generation and social class may have to be considered as they have an influence on the choice of language. Hence, further research related to Punjabi in Thai-Sikh community in Thailand should be conducted both in quantitative and qualitative in order to gain the insights about language choice, language shift and language maintenance in the community.

\section{References}

David, M.K., Ibtisam M. H

Naji and S. Kaur. 2003.

Language maintenance or language

shift among the Punjabi Sikh

community in Malaysia?

International Journal of the

Sociology of Language (Online)

16:1-24.

Dumanig, F.P, M.K. David and

T. Shanmuganathan. 2013.

Language choice and language

policies in Fillipino-Malaysian

families in multilingual Malaysia.

Journal of Multilingual and

Multicultural Development

34.6:582-596

Holmes, J. 2001. Introduction to Socioloinguistics. $\left(2^{\text {nd }}\right.$ ed.). Hallow:

Pearson Education Limited.

Fishman, J. A. 1972. Advances in

Sociology of Language.

Paris:Mouton.
Greenfield, L. 1972. Situational measures of normative language view in relational to person, place, and topic among Puerto Rican bilinguals. In Advances in the Sociology of Language, edited by Joshua A Fishman, pp. $17-35$. The Hague: Mouton.

Grewal, J.S. 1991. The New Cambridge History of India: The Sikhs of the Punjab. Cambridge: Cambridge University Press.

Kingsley, L. 2013. Language choice in multilingual encounters in transnational workplaces. Journal of Multilingual and Multicultural Development. 34.6: 533-548

Parasher, S. N. 1980. Mother-tongue English diglossia: A case study of educated Indian bilinguals' language use. Anthropological Linguistics 22.4: 151 - 168.

Rahman, M. 2008. Patterns of language choice in the domain of office among the Malaysian University undergraduates. Language in India 8

Rasinger, S.M. 2010. Ethnolinguistic vitality and language use amongst Eastern European migrants in East Anglia. Journal of Multilingual and Multicultural Development. 31.3: 287-300.

Stewart, W. A. 1968. Sociolinguistic typology of multilingualism. In The Sociology of Language: an Interdisciplinary Social Science Approach to Language in Society, edited by Joshua A. Fishman, Rowley, Mass: Newbury House. 531-545 
MANUSYA: Journal of Humanities Regular 17.1, 2014

Yahya, F.B. and A. Kaur. 2011. The

Migration of Indian Human Capital:

The Ebb and Flow of Indian

Professionals in Southeast

Asia. Oxon: Rutledge.

Yeh, H.N, H.C. Chan and Y.S. Cheng. 2004. Language use in Taiwan: language proficiency and domain analysis. Journal of Taiwan Normal University 49.1: 75-108 